\title{
AlN ceramics processed by aqueous slip casting
}

\author{
S.M. Olhero \\ Department of Ceramics and Glass Engineering, Centro de Investigação em Materiais Cerâmicos $e$ \\ Compósitos, CICECO, University of Aveiro, 3810-193 Aveiro, Portugal \\ P. Miranzo \\ Instituto de Cerámica y Vidrio, Consejo Superior de Investigaciones Cientificas CSIC, Campus de \\ Cantoblanco, 28049 Madrid, Spain \\ J.M.F. Ferreira ${ }^{\text {a) }}$ \\ Department of Ceramics and Glass Engineering, Centro de Investigação em Materiais Cerâmicos e \\ Compósitos, CICECO, University of Aveiro, 3810-193 Aveiro, Portugal
}

(Received 8 April 2005; accepted 10 March 2006)

\begin{abstract}
Fully dense aluminium nitride (AlN) ceramics consolidated by aqueous slip casting were obtained after sintering at $1750{ }^{\circ} \mathrm{C}$ for $2 \mathrm{~h}$. The obtained samples were characterized by Vickers hardness $(1000 \mathrm{Hv})$, flexural strength $(200 \mathrm{MPa})$ and thermal conductivity $(115 \mathrm{~W} / \mathrm{mK}) . \mathrm{YF}_{3}$ and $\mathrm{CaF}_{2}$ were used as sintering additives in total amounts ranging from 5 to $7 \mathrm{wt} \%$ in $\mathrm{YF}_{3} / \mathrm{CaF}_{2}$ weight ratios of $1.25,1.5$, and 2 . The compatibility between the thermochemically treated AlN powder and the sintering additives in the aqueous suspensions was investigated by rheological and zeta potential measurements. Highly concentrated (50 vol\%) and well-dispersed suspensions could be prepared and used to consolidate homogeneous green bodies by slip casting. The phosphate species used to protect the surface AlN particles against hydrolysis could no longer be detected at temperatures higher than $1400{ }^{\circ} \mathrm{C}$. X-ray diffraction results revealed that all the new crystalline phases formed upon sintering belong to the system $\mathrm{Al}-\mathrm{Y}-\mathrm{O}-\mathrm{Ca}$, but their specific compositions as well as the thermal properties of the sintered materials were shown to depend on the total amount and ratio of sintering aids.
\end{abstract}

\section{INTRODUCTION}

Aluminium nitride is an interesting ceramic material due to its good thermal conductivity, low-dielectric loss, and thermal expansion behavior matching that of silicon. $^{1,2}$ These properties are very important for applications as substrates for highly integrated microelectronic packaging and have motivated a large number of studies aiming at property optimization and establishing a better understanding of the relationships between processing, microstructural features, and final properties. ${ }^{3-5}$

Because of the covalent bonds, AlN has a low diffusivity and requires a high temperature $\left(1900-2000{ }^{\circ} \mathrm{C}\right.$ ) for sintering. The use of sintering aids is the approach more extensively studied to enhance AIN densification at relatively lower temperatures. The additives more frequently used in the sintering of aluminium nitride are

\footnotetext{
a) Address all correspondence to this author.

e-mail: jmf@cv.ua.pt

DOI: $10.1557 / J M R .2006 .0301$
}

$\mathrm{Y}_{2} \mathrm{O}_{3}$ and $\mathrm{CaO}^{6-9}$ which provide low-melting point liquids in reaction with $\mathrm{Al}_{2} \mathrm{O}_{3}$ on the surface of AlN particles. These liquids crystallize on cooling to calcium aluminates for $\mathrm{CaO}$ additives and yttrium aluminates for the $\mathrm{Y}_{2} \mathrm{O}_{3}$ additive. However, since the presence of oxygen is detrimental for thermal conductivity, many efforts have been made to use sintering aids without oxygen in the composition. ${ }^{10-12}$ Other sintering conditions, such as atmosphere, furnace, sintering temperature and holding time are also crucial to eliminate oxygen from the AlN lattice or grain boundaries. Manipulating all of these factors in the proper way can eliminate the major defects and, consequently, improve the thermal conductivity, the most important property of this material. ${ }^{3-5}$ In fact, thermal conductivities of aluminium nitride often differ significantly from the theoretical value $(320 \mathrm{~W} / \mathrm{mK})$ because several existing defects, such as pores and grain boundary segregations, as well as point defects within the AlN lattice, cause a considerable decrease of thermal conductivity.

Obviously, the quality of ceramic processing based on powder technology, including many steps from the 
preparation of raw materials to the sintering of shaped components, is a key point. Each step is, in different ways, crucial for the ultimate material properties. The quality of the starting powders, particle size, particle size distribution, and particle shape are crucial factors, which, in an integrated way influence the final material properties. ${ }^{13,14}$ Moreover, the use of wet consolidation technologies such as slip casting, which allow the forces between particles within a liquid to be controlled, increase the packing ability of a given powder and consequently the final material homogeneity, density, and mechanical strength. ${ }^{15-20}$ An effective breakdown of particle agglomerates in the preparation of the powder suspension, an effective stabilization of the particles, and optimized casting conditions will favor the densification process. Furthermore, when powders with different particle size distributions and surface chemistry properties are to be mixed, as in the case of suspensions in the presence of small quantities of sintering aids, colloidal shaping techniques offer advantages for distributing all the components homogeneously.

Because of the well-known reactivity of AlN powders with water, organic solvents are usually preferred for colloidal processing of AlN-based materials. However, organic solvents are expensive, unsafe, and volatile, requiring the control of emissions into the atmosphere. These drawbacks pose new challenges to the scientific community, and much research has been undertaken in recent years aimed at replacing the traditional organic solvents with water ${ }^{21-27}$ and sintering AlN powders at temperatures lower than those typically used. ${ }^{28-32}$ The achievement of these goals would have positive impacts at different levels (scientific, technologic, environment, economic, health, and other societal aspects).

The present work had a 4-fold objective: (i) study the dispersing ability of a thermochemically treated AIN powder and of $\mathrm{YF}_{3}$ and $\mathrm{CaF}_{2}$ as sintering additives in aqueous media, (ii) prepare highly concentrated and low viscosity suspensions suitable to consolidate green bodies by slip casting, (iii) investigate the influence of total amount and the ratio of sintering aids on sintering ability and on the final properties of AlN ceramics, and (iv) significantly decrease the usual temperatures required for sintering AlN ceramics.

\section{EXPERIMENTAL PROCEDURE}

\section{A. Material and characterization techniques}

The AlN powder used was supplied by Starck (Grade C, H.C. Starck, Berlin, Germany). The powder was thermochemically treated with aluminium di-hydrogenphosphate (Bindal A, TKI, Hrastnik, Slovenia) species following a procedure reported elsewhere. ${ }^{21,25} \mathrm{CaF}_{2}$ (Grade-325 mesh, 99.9\%, Aldrich, Steinheim, Germany; $\rho=3.18$ $\left.\mathrm{g} / \mathrm{cm}^{3}\right)$ and $\mathrm{YF}_{3}\left(99.9 \%\right.$, Aldrich, $\left.\rho=4.01 \mathrm{~g} / \mathrm{cm}^{3}\right)$ used as sintering additives underwent a previous planetary milling process in ethanol for 22 and $48 \mathrm{~h}$, respectively. The aim was to deagglomerate them and reduce their particle sizes as much as possible to enhance the degree of homogeneity and obtain a good distribution of the sintering additives in aqueous suspensions of AlN. A polyacrilic acid (Duramax 3005, Rohm and Haas, Lauterbourg, France) was used as the dispersant.

The particle size distributions of all the raw materials were measured by a laser scattering technique using a Coulter LS230 particle size analyzer (Coulter LS230, Buckinghamshire, UK). The zeta-potential measurements of the AlN-treated powder and of the sintering aids $\left(\mathrm{YF}_{3}\right.$ and $\left.\mathrm{CaF}_{2}\right)$ were performed in the absence and in the presence of dispersant using either a Brookhaven Zeta meter (Brookhaven ZetaPlus, Holtsville, NY) or a Coulter (Delsa $440 \mathrm{Sx}$, Coulter). The powders were suspended in distilled water, and each suspension was divided into two equal parts for increasing and decreasing $\mathrm{pH}$ runs (by using $\mathrm{NaOH}$ or $\mathrm{HCl}$ solutions, respectively, to adjust the $\mathrm{pH}$ values).

\section{B. Preparation and characterization of suspensions}

Based on the electrophoretic measurements and on some results already reported, ${ }^{21,22}$ aqueous suspensions with 50 vol\% powder mixtures containing different weight proportions of $\mathrm{AlN} / \mathrm{CaF}_{2} / \mathrm{YF}_{3}$ were prepared using the optimized dispersion conditions (1 wt \% Duramax 3005). Table I summarizes the different compositions tested and the respective sample codes. The as-prepared suspensions were deagglomerated during $24 \mathrm{~h}$ in a polyethylene bottle containing Teflon balls. Rheological properties of the suspensions were determined using a rotational Rheometer (Bohlin C-VOR Instruments, Worcestershire, UK). The measuring configuration adopted was a cone and plate $\left(4^{\circ}, 40 \mathrm{~mm}\right.$, and gap of $150 \mu \mathrm{m})$, and flow measurements were conducted between 0.1 and $800 \mathrm{~s}^{-1}$.

\section{Preparation and characterization of the green slip-cast and sintered bodies}

The slurries prepared as described above were poured into plastic rings that were placed on absorbent plaster

TABLE I. Sample compositions and the respective sample codes.

\begin{tabular}{cccc}
\hline \hline Sample codes & $\begin{array}{c}\mathrm{AIN} \\
(\mathrm{wt} \%)\end{array}$ & $\begin{array}{c}\mathrm{YF}_{3} \\
(\mathrm{wt} \%)\end{array}$ & $\begin{array}{c}\mathrm{CaF}_{2} \\
(\mathrm{wt} \%)\end{array}$ \\
\hline $\mathrm{A}$ & 95 & 0 & 5 \\
$\mathrm{~B}$ & 97 & 3 & 0 \\
$\mathrm{C}$ & 97 & 2 & 1 \\
$\mathrm{D}$ & 95 & 3 & 2 \\
$\mathrm{E}$ & 94 & 4 & 2 \\
$\mathrm{~F}$ & 93 & 4 & 3 \\
\hline \hline
\end{tabular}


plates to obtain cylindrical cakes with a thickness of about 3-4 mm. For flexural strength measurements, small test bars with average dimensions of $4 \times 5 \times$ $50 \mathrm{~mm}^{3}$ were prepared by slip casting. The green bodies were left to dry at room temperature overnight and then at $80{ }^{\circ} \mathrm{C}$ for $24 \mathrm{~h}$. The resulting green bodies were embedded in a powder mixture of $80 \mathrm{wt} \% \mathrm{AlN}-20 \mathrm{wt} \% \mathrm{BN}$ in a closed graphite crucible and sintered in a furnace with a graphite heating element (Termolab, Águeda, Portugal) under flowing nitrogen atmosphere according to the following heating schedule: $20^{\circ} \mathrm{C} / \mathrm{min}$ up to $1250{ }^{\circ} \mathrm{C}, 10^{\circ} \mathrm{C} / \mathrm{min}$ from 1250 to $1650{ }^{\circ} \mathrm{C}, 1 \mathrm{~h}$ holding time at $1650^{\circ}, 5^{\circ} / \mathrm{min}$ up to $1750^{\circ} \mathrm{C}$ with $2 \mathrm{~h}$ holding at this temperature.

The densities of the green and sintered bodies were measured according to Archimedes' method by immersion in mercury and diethyl-phthalate, respectively. The crystalline phases of the sintered specimens were identified using x-ray diffraction (XRD; Rigaku, Tokyo, Japan) with $\mathrm{Cu} \mathrm{K} \mathrm{K}_{\alpha}$ radiation. The microstructure of fracture surfaces was observed by scanning electron microscopy (SEM; Hitachi S-4100, Tokyo, Japan). Grain boundaries were investigated by transmission electron microscopy (TEM; Hitachi, 9000 NA). The thermal diffusivity $(\alpha)$ was measured by the laser flash method using a commercial instrument (Thermaflash 2200, Holometrix, Bedford, MA). Disk-shaped samples $12.7 \mathrm{~mm}$ in diameter and 1-2 mm thick were used for these measurements. The thermal conductivity $(K)$ of the tested materials was determined from Eq. (1):

$$
K=\alpha C_{\mathrm{p}} \rho,
$$

where $C_{\mathrm{p}}$ is the heat capacity assumed to be the same as that for pure dense aluminium nitride at $25^{\circ} \mathrm{C}\left(\sim 0.8 \mathrm{~J} \mathrm{~g} \mathrm{~g}^{-1}\right.$ $\left.\mathrm{K}^{-1}\right)$ ], and $\rho$ is the density of the material. Flexural strength was measured in a series of 25 specimens with average dimensions of $3 \times 4 \times 40 \mathrm{~mm}$ using a three-point bending device and Shimadzu instrument (Shimadzu, Kyoto, Japan) at a strain rate of $0.5 \mathrm{~mm} / \mathrm{min}$. For all the samples, the load-displacement curves presented an elastic region ending with brittle fracture. Vickers microhardness tests were carried out using a Shimadzu microhardness tester (Shimadzu, Dataletty 150) with a microscope attached. Polished AlN samples were indented with a Vickers diamond pyramidal indenter with a square base and $136^{\circ}$ pyramidal angles. The load was $0.2 \mathrm{kgf}$. Several indentations were made, and the averaged micro hardness values were taken for the analysis.

\section{RESULTS}

\section{A. Characterization and deagglomeration of the powders}

In the slip-casting process, one of the most important features of any powder system is the manner by which individual particles pack together in the powder compact. Particle size and particle size distribution are important factors that influence the particle packing and, consequently, the sintering behavior of ceramic bodies. Moreover, fine divided particles of the sintering aids are crucial for obtaining a homogeneous viscous liquid phase that promotes mass transport. Due to these requests, sintering aids were previously submitted to a milling process to reduce the size of agglomerates and coarser particles. After milling, $\mathrm{CaF}_{2}$ exhibited two particle populations, the main one centered at $\sim 0.65 \mu \mathrm{m}$ and the other one at $\sim 2 \mu \mathrm{m}$. In the same manner, $\mathrm{YF}_{3}$ after milling exhibited a bimodal distribution with the finer and most intense one centered at $\sim 0.6 \mu \mathrm{m}$ and the coarser one centered at $\sim 3 \mu \mathrm{m}$.

\section{B. Dispersing ability of the powders and characterization of the suspensions}

The dispersing ability of the powders in water was accessed by electrophoretic and rheological measurements. Figure 1 shows the results of zeta potential versus $\mathrm{pH}$ measurements in the absence [Fig. 1(a)] and in the presence of $1 \mathrm{wt} \%$ dispersant [Fig. 1(b)].

The basic surface characteristics of $\mathrm{CaF}_{2}$ and $\mathrm{YF}_{3}$ powders are evident from Fig. 1(a), exhibiting isoelectric points $\left(\mathrm{pH}_{\mathrm{IEP}}\right)$ at $\mathrm{pH} \sim 11$ and $\mathrm{pH} \sim 10$, respectively. However, the positive zeta potential values increase faster in the case of the $\mathrm{YF}_{3}$ powder. Thermochemically treated AlN powder (AlN-TC) shows $\mathrm{pH}_{\text {IEP }} \sim 5.5$, lower than
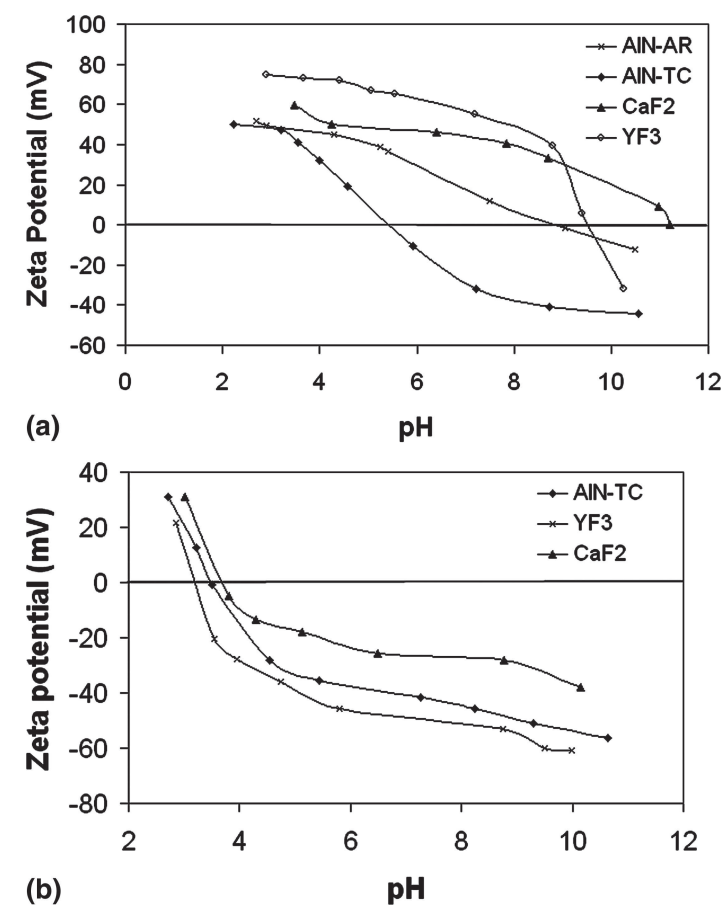

FIG. 1. Zeta potential of the AlN-treated, $\mathrm{YF}_{3}$ and $\mathrm{CaF}_{2}$ powders: (a) in the absence of dispersant and (b) with added $1 \mathrm{wt} \%$ dispersant. 
that of the AlN powder as received (AlN-AR), which shows a $\mathrm{pH}_{\text {IEP }}$ near 9. These results are according to other values reported in literature. ${ }^{21}$

Figure 1(b) shows that adding $1 \mathrm{wt} \%$ anionic dispersant Duramax 3005 caused significant shifts in the values of $\mathrm{pH}_{\mathrm{IEP}}$ toward the acidic range, especially in the case of sintering additives. At the inherent $\mathrm{pH}$ of the suspensions ( $\mathrm{pH}$-8.5), the dissociated polyanionic groups will strongly adsorb at the surface of the positively charged particles of $\mathrm{CaF}_{2}$ and $\mathrm{YF}_{3}$ powders, reversing the surface charge signal. These results indicate that strong repulsive interaction forces between the particles of all dispersed components ( $\mathrm{AlN}, \mathrm{YF}_{3}$ and $\mathrm{CaF}_{2}$ ) will predominate in the presence of $1 \mathrm{wt} \%$ dispersant at the inherent $\mathrm{pH}$ of the suspensions, keeping the particles away from each other and consequently promoting deflocculation. Duramax 3005 was revealed to be a strong surface charge modifier enhancing the negative zeta potential for all the powder components and giving satisfactory high absolute zeta potential values to enable the preparation of highly concentrated suspensions.

The compatibility between the sintering aids and the treated AlN powder in aqueous media was also tested by rheological measurements using highly concentrated suspensions. When the reference suspension without additives was compared with the one containing the highest amount of sintering additives tested $\left(4 \mathrm{wt} \% \mathrm{YF}_{3}+3 \mathrm{wt} \%\right.$ $\mathrm{CaF}_{2}$ ), it was observed that both suspensions displayed moderate shear thinning characteristics along the typical low shear rate range involved in the slip casting process. In summary, no significant differences in viscosity were evident, indicating that a good compatibility among all the dispersed powders had been obtained. These observations are consistent with the results of zeta-potential measurements presented in Fig. 1(b).

Measuring the green densities of the slip cast samples is yet another way to evaluate the dispersion degree of the powders in the suspension because a better dispersion means a higher ability for particles packing during slip casting. Table II shows the relative density (percentage of theoretical density, \% TD) of the green bodies prepared from the suspensions with a total solids loading of $50 \mathrm{vol} \%$ of the different compositions tested (see Table I).

TABLE II. Green density of the AIN samples obtained by slip casting.

\begin{tabular}{cl}
\hline \hline Samples & $\begin{array}{c}\text { Green density } \\
(\% \mathrm{TD})\end{array}$ \\
\hline $\mathrm{A}$ & $62.0 \pm 0.9$ \\
$\mathrm{~B}$ & $64.8 \pm 0.4$ \\
$\mathrm{C}$ & $62.7 \pm 0.04$ \\
$\mathrm{D}$ & $65.6 \pm 0.3$ \\
$\mathrm{E}$ & $63.9 \pm 0.2$ \\
$\mathrm{~F}$ & $66.3 \pm 0.03$ \\
Without additives & $61.9 \pm 1.3$ \\
\hline \hline
\end{tabular}

The high green density obtained for all samples emphasizes the good dispersion level of the suspensions as well as favorable colloidal interactions between the particles of all the components. The composition without sintering additives presents the lowest density, although a value of $61.9 \mathrm{wt} \%$ is a good indicator of high particle packing. The green density improved in the presence of sintering additives; the highest value $(\sim 66 \mathrm{wt} \%)$ was observed for the composition $\mathrm{F}$ with the highest contents of sintering additives. The comparison of samples A and B with added single sintering additives, $5 \mathrm{wt} \% \mathrm{CaF}_{2}$ and 3 $\mathrm{wt} \% \mathrm{YF}_{3}$, respectively, leads to the conclusion that $\mathrm{YF}_{3}$ favors the achievement of higher green density values. Considering the similarities between the particle size distributions of both sintering additives after milling, the observed differences are likely due to the different specific gravity values of the sintering additives and a higher degree of stabilization obtained in the case of added $\mathrm{YF}_{3}$. As a matter of fact, at the inherent $\mathrm{pH}$ of the suspensions $(\mathrm{pH} \sim 8.5)$ in the presence of $1 \mathrm{wt} \%$ Duramax, $\mathrm{YF}_{3}$ presents higher zeta potential values than $\mathrm{CaF}_{2}$ or AlN. Strong repulsive forces among particles keep them away from each other and consequently improve the degree of stabilization of the suspension and enhance particle packing.

\section{Characterization of the AIN sintered samples}

Table III presents some properties (sintered density, thermal conductivity, Vickers hardness, and flexural strength) of sintered ceramics obtained by aqueous slip casting. The data of thermal conductivity were corrected to zero porosity using Klemens' equation ${ }^{33}$ to better discriminate the effect of porosity on thermal conductivity.

Except the pure AIN samples that presented a relatively low sintered density $(\sim 80 \%)$ and the sample with added $5 \mathrm{wt} \% \mathrm{CaF}_{2}$ (composition $\mathrm{A}, \sim 99 \%$ ), all the other compositions exhibit high densification levels $(>99.5 \%$ TD), which tend to increase with an increase in the total amount of sintering additives. Nearly fully dense materials were obtained for compositions D and E. However, compositions $\mathrm{B}$ and $\mathrm{C}$ with the lowest total amount of sintering additives ( $3 \mathrm{wt} \%)$ are denser ( $>99.5 \% \mathrm{TD})$ than composition A (99\% TD) with $5 \mathrm{wt} \%$, the same total amount as in the fully dense composition D (100\% TD). For composition $\mathrm{F}$ with the highest amount of sintering additives, the sintering density decreased (99.5 wt\% TD), probably caused by an excess of secondary phases. These observations led to the conclusion that both the composition and the amount of sintering additives play important roles. In the system $\mathrm{CaF}_{2}-\mathrm{YF}_{3}$, the latter component is clearly the most effective one.

Incomplete densification might be caused by the incomplete oxygen consumption at the grain boundaries and an insufficient amount of liquid phase formed. ${ }^{3,29}$ This easily explains the lowest density of pure AlN 
TABLE III. Final properties (sintered density, thermal conductivity, hardness, and flexural strength) of the AIN samples.

\begin{tabular}{|c|c|c|c|c|}
\hline Samples & $\begin{array}{c}\text { Sintered density } \\
\text { (\%TD) }\end{array}$ & $\begin{array}{l}\text { Thermal conductivity } \\
\qquad \mathrm{W} \mathrm{m} \mathrm{m}^{-1} \mathrm{~K}^{-1}\end{array}$ & $\begin{array}{l}\text { Microhardness } \\
\text { (Vickers) }\end{array}$ & $\begin{array}{c}\text { Flexural strength } \\
(\mathrm{MPa})\end{array}$ \\
\hline $\mathrm{A}$ & $99.01 \pm 0.74$ & $93.7 \pm 4.68$ & $962.3 \pm 28.16$ & $128.5 \pm 15.9$ \\
\hline $\mathrm{B}$ & $99.6 \pm 0.76$ & $75.0 \pm 3.75$ & $1062.1 \pm 64.03$ & $135.5 \pm 14.0$ \\
\hline $\mathrm{C}$ & $99.8 \pm 0.56$ & $77.9 \pm 3.89$ & $1100.1 \pm 51.37$ & $157.5 \pm 20.9$ \\
\hline $\mathrm{D}$ & $100.1 \pm 0.08$ & $113.0 \pm 5.65$ & $971.3 \pm 38.90$ & $178.7 \pm 22.8$ \\
\hline $\mathrm{E}$ & $99.9 \pm 0.21$ & $115.0 \pm 5.75$ & $950.2 \pm 27.30$ & $218.8 \pm 18.7$ \\
\hline $\mathrm{F}$ & $99.5 \pm 0.18$ & $108.0 \pm 5.40$ & $908.9 \pm 47.18$ & $203.1 \pm 21.3$ \\
\hline Without additives & $80.2 \pm 2.97$ & $\ldots$ & $\ldots$ & $\ldots$ \\
\hline
\end{tabular}

\section{$\mathrm{CaF}_{2} \cdot \mathrm{YF}_{3}$}

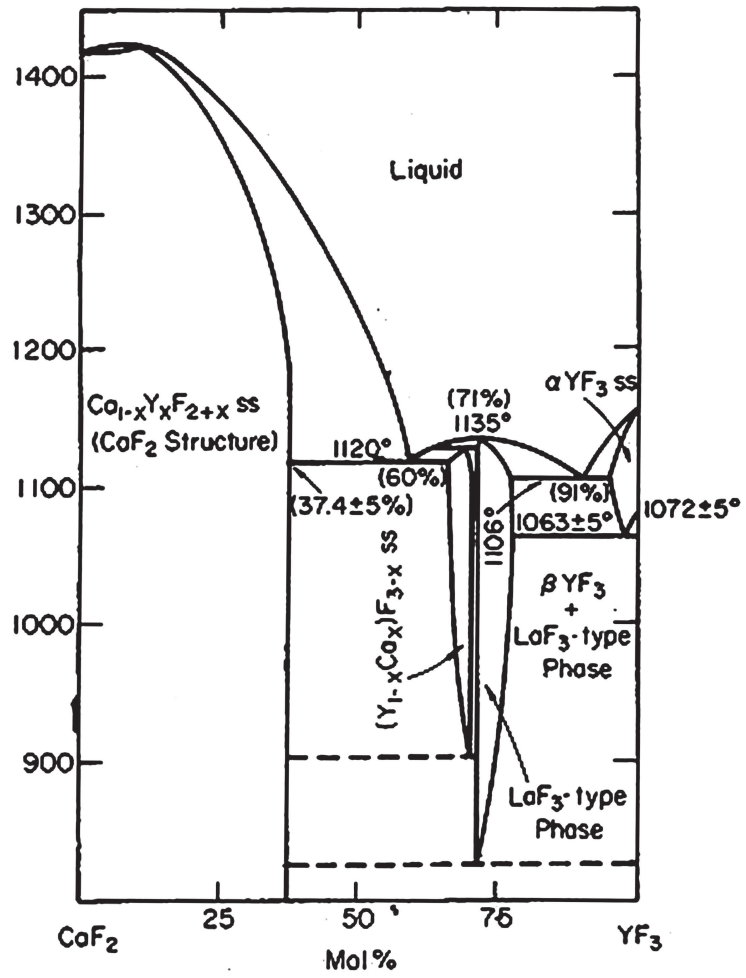

FIG. 2. Binary phase diagram of the $\mathrm{CaF}_{2}-\mathrm{YF}_{3}$ system. $^{34}$

samples (80\% TD). According to the phase diagram of Fig. $2,{ }^{34}$ the mixtures $\mathrm{CaF}_{2}+\mathrm{YF}_{3}$ in the ratios tested in the present work should melt between 1200 and $1300{ }^{\circ} \mathrm{C}$, whereas in the case of sample A with a lower relative density (99\% TD), the formation of a liquid phase is expected to occur only at higher temperatures of about $1400{ }^{\circ} \mathrm{C}$. The sintering additives react with oxygen present at the grain boundaries, which exerts a deleterious sintering effect by shifting the appearance of the liquid phase to temperatures higher than those predicted from Fig. $2 .^{3,11}$ In any case, a liquid phase is present at the sintering temperatures used in this investigation $\left(1750{ }^{\circ} \mathrm{C}\right)$. During sintering, the liquid phase attempts to occupy the lowest free energy position, thereby flowing to the finest capillaries, which have the highest energy per unit volume. When there is insufficient liquid to fill all the pores, the liquid attempts to pull the particles together to minimize the free energy. On the other hand, dissolution of the alumina present at the surface of AlN particles and the re-precipitation of the $\mathrm{Y}-\mathrm{Al}-\mathrm{O}$ phases improve the densification behavior due to the wetting behavior of these phases. Complete wetting is a requirement for liquid phase sintering. However, when good wetting is observed, higher amounts of oxygen are present at the grain boundaries, and consequently, the thermal conductivity decreases. ${ }^{35}$

Figure 3 shows the microstructures of the polished samples (back scattering images) of the different compositions, where white color corresponds to the secondary phases and the black one to the AlN grains. All the microstructures confirm the density results presented in Table III. Except sample A, which presents some porosity associated with lower amounts of secondary phases between the grains, all samples present full or nearly full density. Intergranular liquid phases are located at the AlN grain boundaries connecting the grains, and their thickness seems to increase with an increase in the total amount of sintering aids, independent of the ratio between both. Because higher amounts of secondary phases could improve densification behavior, the density value is lower in the case of sample $\mathrm{F}$ due to the lower theoretical density of the secondary phases when compared with crystalline AlN.

The sintering additive compositions seem to affect the mechanical properties through the amount of intergranular phases formed, the volume fraction of porosity, and the grain size distribution, as Table III and Fig. 3 suggest. The increasing amount of intergranular phases and the concomitant increase in sintered density enhanced the flexural strength of the AlN. This is according to the microstructural observations on fracture surfaces (not shown) that clearly showed a number of transgranularly fractured grains, indicating strong bonding and high strength of the intergranular phase. The increase in the amount of sintering additives resulted in a decrease of microhardness due to the lower hardness of the secondary phases between AlN grains in comparison to that of crystalline AlN grains.

Table III and the results of XRD analysis (Fig. 4) show that thermal conductivity is sensitive not only to density 

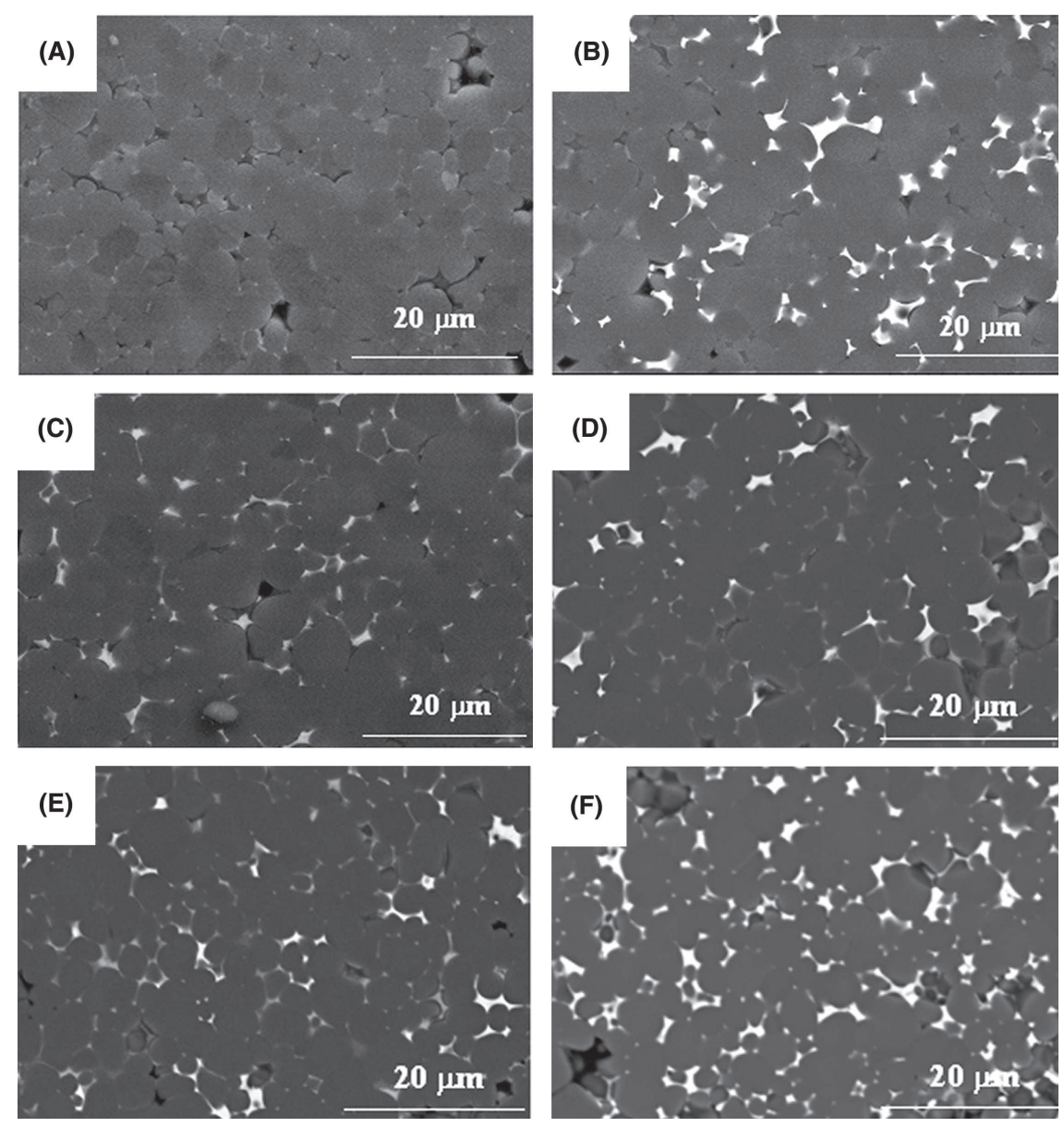

FIG. 3. Backscattering images of the polished AlN samples (A, B, C, D, E, and F) after sintering at $1750{ }^{\circ} \mathrm{C}$ for $2 \mathrm{~h}$.

and microstructural features (grain size, amount of intergranular phases) but also, mainly, to the secondary crystalline phases formed. In fact, thermal conductivity varied with the total amount and ratio of sintering additives. Compositions $\mathrm{B}$ and $\mathrm{C}$, containing a total amount of sintering aids of only $3 \mathrm{wt} \%$, present the lowest thermal conductivity values. Composition $\mathrm{C}$ with a combination of the two additives (2 $\mathrm{wt} \% \mathrm{YF}_{3}$ and $1 \mathrm{wt} \% \mathrm{CaF}_{2}$ ) is slightly more thermally conductive, although it exhibits a somewhat lower densification. The combination of the two additives is still favorable to thermal conductivity when the total amount of sintering aids was increased to $5 \mathrm{wt} \%$ (compositions $\mathrm{A}$ and $\mathrm{D}$ ). If the given ratio, as in compositions $\mathrm{C}$ and $\mathrm{E}$, was kept but the total amount of sintering aids was increased, thermal conductivity increased. However, further increasing the total amount of sintering aids at the expenses of $\mathrm{CaF}_{2}$ (composition $\mathrm{F}$ ) resulted in slightly lower thermal conductivity.

These results suggest that the total amount of sintering additives of $3 \mathrm{wt} \%$ might be insufficient to fully react with residual oxygen at the surface of AlN particles and to accomplish the oxygen removal from both the lattice and the surface. Contents of sintering additives $<6 \mathrm{wt} \%$ led to excessive amounts of intergranular phases and to changes in the wetting regime. According to the wetting ability, the intergranular phases might be located preferentially at the grain boundaries or in the triple points.

The key condition for obtaining AlN ceramics with high thermal conductivities is the cleaning of the AlN lattice and grain boundaries, i.e., the removal of oxygen from the lattice and grain boundaries to increase the phonon mean free path. During sintering, oxygen covering the surfaces of the AlN particles can diffuse into the lattice to produce aluminium vacancies, which decrease the thermal conductivity of AlN ceramics by scattering phonons. $^{3,36}$ The presence of additives decreases the oxygen defects by two routes: (i) the additives react with the oxygen to form aluminates and thus decrease the oxygen content of the AlN particles, and (ii) a microstructural change occurs as the aluminate de-wets the grain boundaries and segregates to the grain junctions leading to AlN-AlN grain boundary contacts. ${ }^{3}$

To shed light on the influence of the amount of sintering additives on the thickness of the intergranular liquid phase and to analyze their composition and location, TEM analysis with energy dispersive spectroscopy (EDS) results of the AlN samples with different amounts of sintering additives are shown in Fig. 4. 

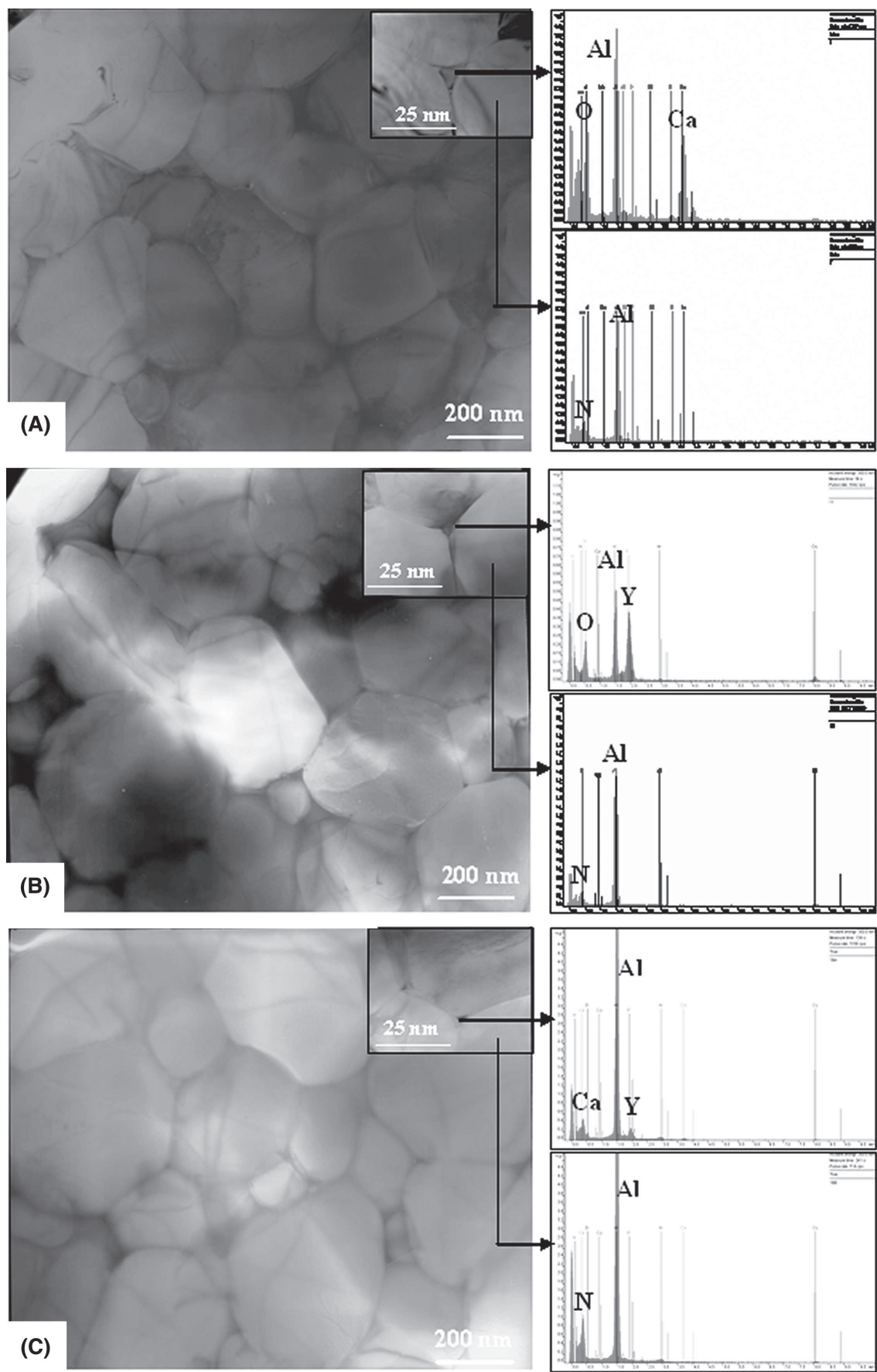

FIG. 4. TEM photographs of the AlN samples and respective chemical analysis by EDS of the grain and grain boundaries (triple points), (continued on next page)

Figure 4 confirms the high degree of densification and shows that the AlN grains are in close contact with each other, mediated by a thin layer of secondary phases at the grain boundaries, the optical contrast of which increases with the $\mathrm{YF}_{3} / \mathrm{CaF}_{2}$ ratio due to the high atomic number of $\mathrm{Y}$ element. For a given ratio, the contrast seems to decrease with increasing total amount of sintering additives, which favors a better integration of the surface oxygen in the secondary phases. The grain boundary phases consist of $\mathrm{Al}, \mathrm{O}$, and $\mathrm{Ca}$ in sample $\mathrm{A}$, containing only $\mathrm{CaF}_{2} ; \mathrm{Al}, \mathrm{O}$, and $\mathrm{Y}$ in sample $\mathrm{B}$, containing only $\mathrm{YF}_{3}$; and $\mathrm{Al}, \mathrm{Y}, \mathrm{Ca}$, and $\mathrm{O}$ in samples containing $\mathrm{YF}_{3}$ and $\mathrm{CaF}_{2}$, as can be observed in the EDS graphs. These results confirm that the chemical composition of the secondary phases varies with the amount and the proportion of sintering additives, which is in good agreement with the findings of other authors. ${ }^{28}$

Comparison of the TEM micrographs of samples A, B, 

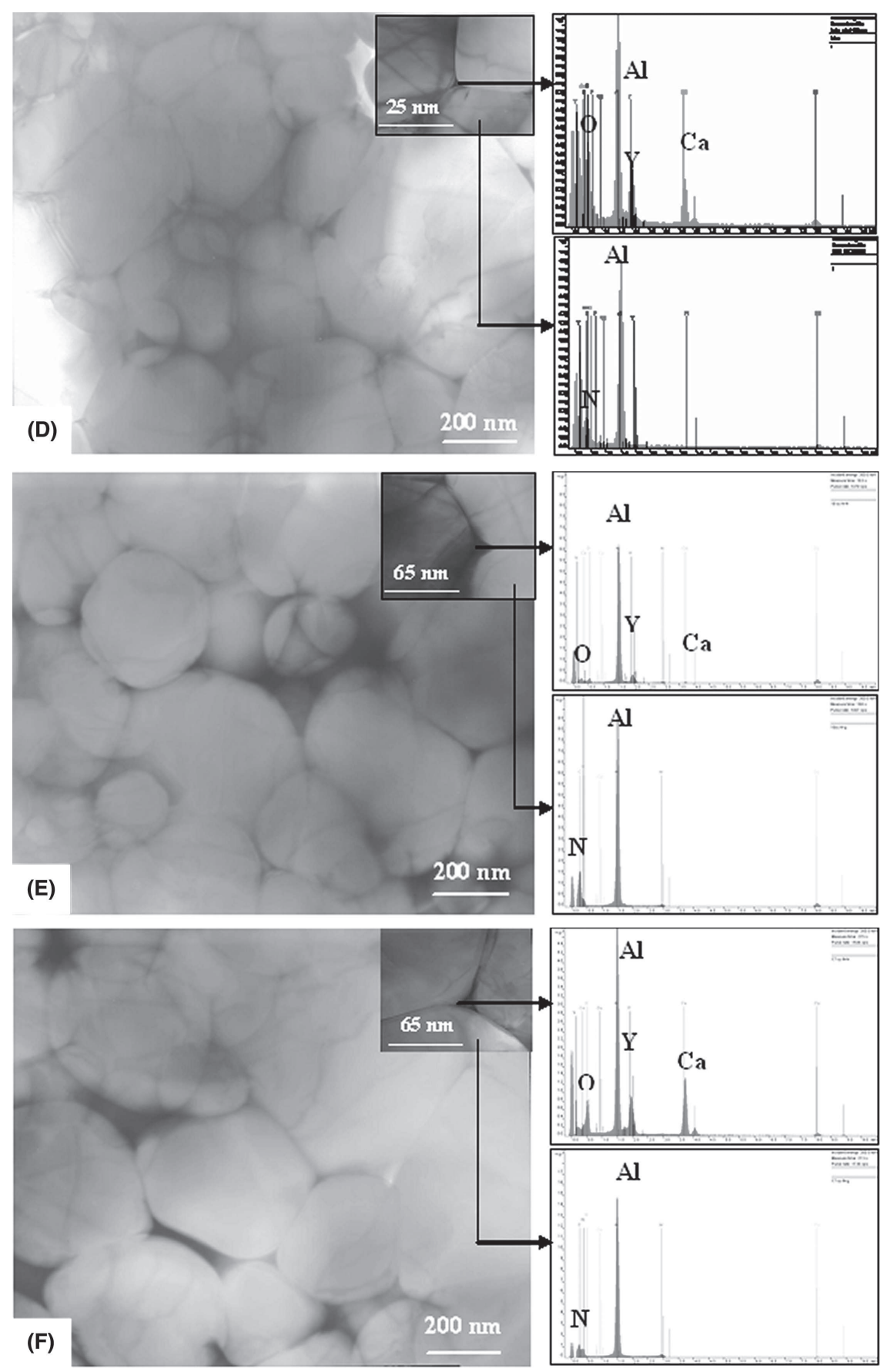

Fig. 4. (continued)

$\mathrm{C}$, and $\mathrm{D}$ confirms that $\mathrm{CaF}_{2}$ alone (sample $\mathrm{A}$ ) or mixed with $\mathrm{YF}_{3}$ in total added amounts of $5 \mathrm{wt} \%$ (sample D) determines a different distribution of the secondary phases. In fact, in all the samples, secondary phases are preferentially located along the AlN boundaries. Although higher amounts of sintering additives could react with all the oxygen present at the surface of AlN particles, the segregation of the secondary phases to the triple points was not verified, probably due to good wetting behavior of the liquid phase with respect to AlN grains. According to Hundere et al., ${ }^{35}$ the wetting ability of the $\mathrm{Y}-\mathrm{Al}-\mathrm{O}$ containing phase on AlN grains was found to be dependent on the content of oxygen impurities on the AlN grain surface. A Y-Al-O containing phase wets an AlN surface if oxide is present because the energy ratio between the liquid-solid surfaces is supposed to be higher for a pure nitride surface than for an AlN surface with oxygen impurities when the liquid is an oxide melt.

The irradiated electron beam scattered over the region 


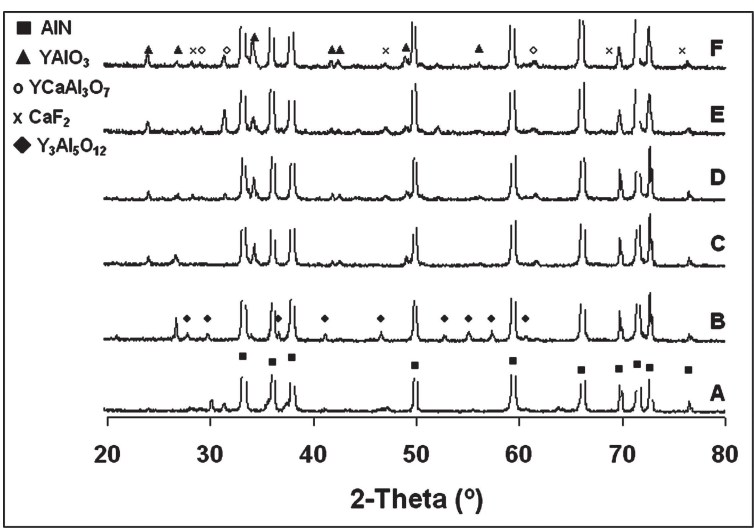

FIG. 5. X-ray diffraction patterns of secondary phases in the AlN samples (A, B, C, D, E, and F) after sintering at $1750{ }^{\circ} \mathrm{C}$ for $2 \mathrm{~h}$.

of the secondary phases of samples $\mathrm{B}$ to $\mathrm{F}$, indicating that some of the $\mathrm{Y}$ and $\mathrm{Ca}$ elements form crystalline phases while the remaining elements exist as amorphous film. In sample A, no diffraction pattern was observed. To analyze the secondary phases formed during sintering, XRD analysis of the AlN samples with different amounts and ratio of $\mathrm{YF}_{3}$ and $\mathrm{CaF}_{2}$ sintered at $1750{ }^{\circ} \mathrm{C}$ was performed. Minor peaks corresponding to secondary grain boundary phases could be detected together with much stronger AlN peaks. When plotted on the same scale, the peaks of secondary phases appeared more or less flat due to the high difference in the intensity. Therefore, the peaks of AlN were partially cut to allow the peaks of secondary phases to be distinguished, as shown in Fig. 5.

The secondary phase formed in sample B containing only $\mathrm{YF}_{3}$ as a sintering aid is predominantly yttriumaluminium garnet (YAG) $\mathrm{Y}_{3} \mathrm{Al}_{5} \mathrm{O}_{12}$, but in the samples containing $\mathrm{YF}_{3}$ and $\mathrm{CaF}_{2}$ mixtures, the major secondary phase is yttrium-aluminium perovskite (YAP) $\mathrm{YAlO}_{3}$ with a trace of $\mathrm{CaF}_{2}$. The presence of these secondary phases $\mathrm{YAlO}_{3}$ or $\mathrm{Y}_{3} \mathrm{Al}_{5} \mathrm{O}_{12}$ instead of $\mathrm{Y}_{2} \mathrm{Al}_{4} \mathrm{O}_{9}$ explains the relatively low thermal conductivity values measured for all the samples. It has been claimed that when $\mathrm{Y}_{2} \mathrm{Al}_{4} \mathrm{O}_{9}$ is produced instead of $\mathrm{Y}_{3} \mathrm{Al}_{5} \mathrm{O}_{12}$ or $\mathrm{YAlO}_{3}$, the highest thermal conductivity can be achieved. ${ }^{26}$ The presence of an amorphous intergranular phase, as in sample A, or an insufficient amount of sintering additives to dissolve the surface oxygen, as in samples B and C, might provide other reasons to justify the low measured thermal conductivities. Increasing the total amount of sintering additives (samples $\mathrm{E}$ and $\mathrm{F}$ ) increases the amount of secondary phases formed and simultaneously weakens the resolution of AlN XRD peaks. At the same time, thermal conductivity seems to increase first (sample E) and then tends to decrease (sample F), suggesting that a compromise between the amount and nature of the secondary phases should be sought to enhance thermal conductivity.
Alternative ways to improve thermal conductivity involve higher sintering temperatures and longer sintering times, which favor cleaning the grain boundaries by removing oxygen impurities, ${ }^{28,31}$ but the processing costs will increase.

\section{CONCLUSIONS}

The results presented in this work lead to the conclusion that fully dense and relatively high thermal conductive AlN ceramics can be consolidated by slip casting from aqueous suspensions and pressureless sintering at a temperature as low as $1750{ }^{\circ} \mathrm{C}$ for a short time period of $2 \mathrm{~h}$. This means that the organic solvents typically used to process this material can definitely be replaced by water. It was also shown that both the amount and ratio of the sintering additives play important roles in the microstructural development and in determining the final physical properties of the sintered bodies. The mixture of $4 \mathrm{wt} \% \mathrm{YF}_{3}+2 \mathrm{wt} \% \mathrm{CaF}_{2}$ was the most appropriate combination for the sintering conditions tested; it enabled thermal conductivity as high as $115 \mathrm{~W} / \mathrm{m}$.K to be achieved.

\section{ACKNOWLEDGMENTS}

The first author wishes to thanks to Fundação para a Ciência e Tecnologia of Portugal for the financial support under Grant No. SFRH/BD/8754/2002. Thanks are also due to Project PRAI-Centro for the financial support. The second author is in debt to Mcyt (Ministery of Science and Technology, Spain) Project No. MAT 200306147-C04-01.

\section{REFERENCES}

1. L.M. Sheppard: Aluminium nitride: A versatile but challenging material. Am. Ceram. Soc. Bull. 69, 1801 (1990).

2. A.K. Knudsen: Aluminum nitride. Am. Ceram. Soc. Bull. 74, 97 (1995).

3. A.V. Virkar, T.B. Jackson, and R.A. Cutler: Thermodynamic and kinetic effects of oxygen removal on the thermal conductivity of aluminium nitride. J. Am. Ceram. Soc. 72, 2031 (1989).

4. A. Collange, P. Grosseau, B. Guilhot, J.P. Disson, and P. Joubert: Thermal conductivity of compacted AlN samples. J. Eur. Ceram. Soc. 17, 1897 (1997).

5. P. Greil, M. Kulig, and D. Hotza: Aluminium nitride ceramics with high thermal conductivity from gas-phase synthesized powders. J. Eur. Ceram. Soc. 13, 229 (1994).

6. Y. Ying-Da, A.M. Hundere, R. Hoier, R.E. Dunin-Borkowski, and M-A. Einarsrud: Microstructural characterization and microstructural effects on the thermal conductivity of $\mathrm{AlN}\left(\mathrm{Y}_{2} \mathrm{O}_{3}\right)$ ceramics. J. Eur. Ceram. Soc. 22, 247 (2002).

7. H. Buhr and G. Muller: Microstructure and thermal conductivity of $\operatorname{AlN}\left(\mathrm{Y}_{2} \mathrm{O}_{3}\right)$ ceramics sintered in different atmospheres. J. Eur. Ceram. Soc. 12, 271 (1993). 
8. U. Neumann and T. Reetz: The influence of the anions of calciumcontaining sintering aids for aluminium nitride. J. Eur. Ceram. Soc. 12. 117 (1993).

9. K. Watari, J.H. Hwang, M. Toriyama, and S. Kanzaki: Effective sintering aids for low-temperature sintering of AlN ceramics. J. Mater. Res. 14, 1409 (1999).

10. Y. Liu, H. Zhou, L. Qiao, and Y. Wu: Low-temperature sintering of aluminium nitride with $\mathrm{YF}_{3}-\mathrm{CaF}_{2}$ binary additive. J. Mater. Sci. Lett. 18, 703 (1999).

11. A.M. Hundere and M-A. Einarsrud: Effects of reduction of the Al-Y-O containing secondary phases during sintering of AlN with $\mathrm{YF}_{3}$ additions. J. Eur. Ceram. Soc. 16, 899 (1996).

12. L. Qiao, H. Zhou, and R. Fu: Thermal conductivity of AlN ceramics sintered with $\mathrm{CaF}_{2}$ and $\mathrm{YF}_{3}$. Ceram. Int. 29, 893 (2003).

13. F.F. Lange: Powder processing science and technology for increased reliability. J. Am. Ceram. Soc. 72, 3 (1989).

14. W.E. Lee and W.M. Rainforth: Ceramic Microstructure-Property Control by Processing (Chapman and Hall, London, UK, 1994).

15. M.S. Wolfgang, S.B. Nelson, and L. Bergstrom: Novel powderprocessing methods for advanced ceramics. J. Am. Ceram. Soc. 83, 1557 (2000).

16. F.F. Lange and K.T. Miller: A colloidal method to ensure phase homogeneity in $\beta^{\prime \prime}-\mathrm{Al}_{2} \mathrm{O}_{3} / \mathrm{ZrO}_{2}$ composite systems. $\mathrm{J}$. Am. Ceram. Soc. 70, 896 (1987).

17. J. Lewis: Colloidal processing of ceramics. J. Am. Ceram. Soc. $\mathbf{8 3}$. $2341(2000)$.

18. Z.S. Rak: Advanced shaping techniques in advanced ceramics. Ceram. Forum Int. 77(6), 6 (2000).

19. G. Tarì, J.M.F. Ferreira, and O. Lyckefeldt: Influence of magnesia on colloidal processing of alumina. J. Eur. Ceram. Soc. 17, 1341 (1997).

20. G. Tarì and J.M.F. Ferreira: Colloidal processing of calcium carbonate. Ceram. Int. 24, 527 (1998)

21. S.M. Olhero, S. Novak, K. Krnel, T. Kosmac, and J.M.F. Ferreira: Thermo-chemical surface treatment of AlN powder towards aqueous processing of AlN ceramics. J. Mater. Res. 19, 746 (2004).

22. M. Oliveira, S. Olhero, J. Rocha, and J.M.F. Ferreira: Controlling hydrolysis and dispersing AlN powders in aqueous media. $\mathrm{J}$. Colloid Interface Sci. 261, 456 (2003).

23. S.M. Olhero, M.I.L.L. Oliveira, and J.M.F. Ferreira: Successful strategies for aqueous colloidal shape-forming of nitride-based ceramics. Recent Devel. Coll. Inter. Res. 2, 65 (2004).

24. K. Krnel and T. Kosmac: Reactivity of aluminium nitride powder in dilute inorganic acids. J. Am. Ceram. Soc. 83, 1375 (2000).

25. K. Krnel and T. Kosmac: Protection of AlN powder against hydrolysis using aluminium dihydrogen phosphate. J. Eur. Ceram. Soc. 21, 2075 (2001)

26. Y. Shimizu, J. Hatano, T. Hyodo, and M. Egashira: Ion-exchange loading of yttrium acetate as a sintering aid on aluminium nitride powder via aqueous processing. J.Am. Ceram. Soc. 83, 2793 $(2000)$.

27. X-J. Luo, X-R. Xu, B-L. Zhang, W-L. Li, and H-R. Zhuang: Characteristic and dispersion of a treated AlN powder in aqueous solvent. Mater. Sci. Eng., A 368, 126 (2004).

28. J. Jarrige, K. Bouzouita, C. Doradoux, and M. Billy: A new method for fabrication of dense aluminium nitride bodies at temperatures as low as $1600^{\circ}$ C. J. Eur. Ceram. Soc. 12. 279 (1993).

29. K. Watari, H.J. Hwang, M. Toriyama, and S. Kanzaki: Effective sintering aids for low-temperature sintering of AlN ceramics. J. Mater. Res. 14, 1409 (1999).

30. T.B. Troczynski and P.S. Nicholson: Effect of additives on the pressureless sintering of aluminium nitride between 1500 and $1800{ }^{\circ}$ C. J. Am. Ceram. Soc. 72, 1488 (1989).

31. E. Streicher, T. Chartier, P. Boch, M-F. Denanot, and J. Rabier: Densification and thermal conductivity of low-sinteringtemperature AlN materials. J.Eur. Ceram. Soc. 6, 23 (1990).

32. L. Qiao, H. Zhou, H. Xue, and S. Wang: Effect of $\mathrm{Y}_{2} \mathrm{O}_{3}$ on low temperature sintering and thermal conductivity of AlN ceramics. J. Eur. Ceram. Soc. 23, 61 (2003).

33. P.G. Klemens: Thermal conductivity of inhomogeneous media. High Temp. High Press, 23, 241-248 (1991).

34. R.S. Roth, T. Negas, and P.C. Lawrence: In Phase Diagrams for Ceramists, Vol. 5, edited by G. Smith (American Ceramic Society, Columbus, $\mathrm{OH}, 1983)$, p. 97.

35. A.M. Hundere and M-A. Einarsurd: Microstructural development in AlN $\left(\mathrm{YF}_{3}\right)$ ceramics. J. Eur. Ceram. Soc. 17, 873 (1997).

36. G. Gorzawski, M. Sternitzke, W.F. Muller, A. Berger, and G. Muller: Oxygen enrichment at inversion domain boundaries in aluminium nitride-Influence on thermal conductivity. J. Eur. Ceram. Soc. 15, 95 (1995). 